\title{
The Neurotoxic Effects of Estrogen on Ischemic Stroke in Older Female Rats Is Associated with Age-Dependent Loss of Insulin-Like Growth Factor-1
}

\author{
Amutha Selvamani and Farida Sohrabji \\ Women's Health in Neuroscience Program, Department of Neuroscience and Experimental Therapeutics, Texas A\&M Health Science Center College of \\ Medicine, College Station, Texas 77843
}

\begin{abstract}
Hormone therapy to postmenopausal females increases the risk and severity of ischemic stroke. Our previous work using an animal model of menopause (reproductive senescence) shows that middle cerebral artery occlusion (MCAo) causes a larger cortical-striatal infarct in this older acyclic group compared with younger females. Moreover, although estrogen treatment is neuroprotective in younger females, estrogen paradoxically increases infarct volume in acyclic females. We hypothesized that the neurotoxic effects of estrogen in older females occurs because of decreased availability of IGF-1, a neuroprotectant that decreases with advancing age and is downregulated by estrogen treatment. Our data show that plasma IGF-1 levels are significantly reduced in reproductive senescent females and further reduced by estrogen at all ages. The neuroprotective effect of estrogen on MCAo-induced cortical infarct volume in mature adult female is reversed by intracerebroventricular injections of IGF-1 receptor antagonist JB-1. Similarly, estrogens neurotoxic effects on cortical infarct volume in senescent females is attenuated by concurrent IGF-1 treatment, and reversed when IGF- 1 is infused $4 \mathrm{~h}$ after the onset of ischemia (delayed IGF-1 treatment). Delayed IGF-1/estrogen treatment also suppressed ischemia-induced ERK1 phosphorylation, reduced protein oxidation, and stimulated an early increase in prostaglandin $\mathrm{E}_{2}$ at the infarct site. IGF-1 treatment was only protective in senescent females that received estrogen, indicating that the neuroprotective actions of this peptide require interaction with the steroid hormone receptor. These data support the hypothesis that stroke severity in older females is associated with decreased IGF-1 and further indicate that short-term postischemic IGF-1 therapy may be beneficial for stroke.
\end{abstract}

\section{Introduction}

Stroke is the third major cause of death and the leading cause of long-term disability in the United States. Although men are at greater risk for stroke, older women have a higher risk for stroke than men (Towfighi et al., 2007), more fatal strokes, and greater poststroke disability and mental impairment (Bushnell, 2008). Declining ovarian steroid hormones are thought to contribute to the increased stroke-associated disability and fatality in this group (Roquer et al., 2003; Niewada et al., 2005; Hochner-Celnikier et al., 2005). However, hormone therapy to postmenopausal women significantly increases the risk for stroke (Wassertheil-Smoller et al., 2003; Shumaker et al., 2004), whereas, paradoxically, low-dose oral estrogen-based contraceptives do not significantly increase stroke risk in young women (Petitti et al., 1996; Siritho et al., 2003). These clinical studies suggest that age and the hormonal milieu interact to modify cerebrovascular disease; however, most animal studies

\footnotetext{
Received Feb. 11, 2010; revised March 15, 2010; accepted March 29, 2010.

This work was supported by National Institutes of Health Grants AG027684 and AG028303 (F.S.). We thank Drs. Bake and Lewis for their assistance on the optical imaging studies, Glorian Roman-Cruz, Eneida Male, Ryan Huebinger, and Joseph Kilianski for technical assistance, and Drs. Bake, Lewis, and Miranda (Texas A\&M Health Science (enter) for comments on this manuscript.

Correspondence should be addressed to Farida Sohrabji, Texas A\&M Health Science Center College of Medicine, Neuroscience and Experimental Therapeutics, 228 Reynolds Medical Building, College Station, TX 77843. E-mail: sohrabji@medicine.tamhsc.edu.

D0I:10.1523/JNEUROSCI.0761-10.2010

Copyright $\odot 2010$ the authors $\quad 0270-6474 / 10 / 306852-10 \$ 15.00 / 0$
}

have not recapitulated this age-dependent estrogen effect. In ovariectomized rats, estrogen treatment has been shown to be neuroprotective in some cases (Simpkins et al., 1997; Dubal et al., 1998; Rusa et al., 1999) and neurotoxic in others (Carswell et al., 2004; Gordon et al., 2005). Meta-analyses (Macrae and Carswell, 2006; Strom et al., 2009) suggest that the overall effect of estrogen may depend on the type of ischemia (permanent vs transient), dose and timing of estrogen. Through our recent studies using the endothelin-1 (ET-1) model of middle cerebral artery occlusion (MCAo), we uncovered a novel age-dimorphic effect of estrogen that better mimics the clinical data. In this stroke model, estrogen reduced infarct volume in young ovariectomized females but paradoxically increased infarct volume in acyclic (reproductive senescent) females (Selvamani and Sohrabji, 2008). Thus, this system offers a unique opportunity to decipher the underlying mechanism of the age-dimorphic effects of estrogen in stroke.

We hypothesized that the dimorphic effect of estrogen on young and senescent females is related to the bioavailability of a neuroprotective intermediary product that is downregulated both by advancing age and by estrogen. In view of its actions as a neuroprotectant in stroke models (Schäbitz et al., 2001; Lin et al., 2009), insulin-like growth factor 1 (IGF-1) is an ideal candidate. Low normal levels of IGF-1 are associated with increased morbidity and mortality in ischemic heart disease and stroke (Schwab et al., 1997; Laughlin et al., 2004; Johnsen et al., 2005). Plasma 
IGF-1 levels decrease with advancing age (Waters et al., 2003; Denti et al., 2004) and are further downregulated by estrogen treatment (Friend et al., 1996; Ho et al., 1996). Finally, IGF-1 and estrogen have been shown to act synergistically in experimental models of neurodegenerative diseases (Garcia-Segura et al., 2001).

The present studies therefore tested the hypothesis that circulating IGF-1 levels are reduced because of age in reproductive senescent females and further reduced by estrogen treatment. Additionally, these studies determined whether altering IGF-1 availability to reproductive senescent females would compensate or reverse the deleterious effect of estrogen. Our data indicate that estrogen and IGF-1 interaction is critical for neuroprotection in the ischemic cortex of reproductive senescent females.

\section{Materials and Methods}

Animals. All animals were purchased from Harlan Laboratories, either as young adult virgin females (nulliparous; $3-4$ months; $250 \mathrm{~g} ; n=12$ ) or as proven breeders with either four pregnancies (5-6 months; $230-320 \mathrm{~g}$; $n=24)$ or as retired breeder (9-11 months; $280-350 \mathrm{~g} ; n=72)$. This latter group typically arrive acyclic (usually constant estrus). Daily vaginal smears were performed for 3 weeks on all females to confirm estrus cycling, and retired breeders were assigned to the study as reproductive senescent females when characterized as constant diestrus (undetectable levels of estrogen) for at least 2 weeks. All females were then subject to the ovariectomy surgery and replaced with either a control or $17 \beta$-estradiolcontaining pellet. Therefore, reproductive senescent females are in an estrogen-deficient stage for $4+$ weeks and an estrogen-depleted state for $5+$ weeks ( $2+$ weeks of constant diestrus; 3 weeks of ovariectomy). All animals were maintained in a constant $12 \mathrm{~h}$ dark/light cycle. Food and water were available ad libitum.

Estrous cycle determination. Vaginal smears were obtained daily between 10:00 and 11:00 A.M. Smears, obtained with a cotton swab, were placed on a slide and later examined under a microscope (Olympus; Leeds Instruments; $20 \times$ objective) and staged according to commonly accepted criteria. Smears were obtained over a $14-20 \mathrm{~d}$ period, and rats that persisted in any one stage for $7 \mathrm{~d}$ were considered acyclic. The estrous cycle has four stages: proestrus (round nucleated epithelial cells), estrus (enucleated cornified cells), metestrus (proportional numbers of leukocytes and cornified cells), and diestrus (few cells, predominantly leukocytes, with the presence of thick mucus). Reproductive senescent animals were included in the study if they were in constant diestrus for a period of 2 weeks. Mature adult females had a mean estrus cycle length of $8 \mathrm{~d}$.

Surgeries. All animals were ovariectomized and replaced with a control pellet or $17 \beta$-estradiol-containing pellet, using our previously established procedures (Jezierski and Sohrabji, 2001). Ovaries were removed and $17 \beta$-estradiol pellets $(1.0 \mathrm{mg}) 60 \mathrm{~d}$ time release or control pellets (Innovative Research) were placed subcutaneously before closing the incision. These pellets are designed to maintain a plasma hormone level of $60-80 \mathrm{pg} / \mathrm{ml}$ (Jezierski and Sohrabji, 2001; Nordell et al., 2003). Previous studies have shown that a stable level of plasma estradiol is maintained at 3, 4, and 6 weeks, although a recent study reports a high supraphysiological burst of hormone levels soon after pellet implantation (Singh et al., 2008). Control pellets do not contain hormone. At killing, the uterus was removed, cleaned of fat, and weighed to determine the effectiveness of estrogen replacement.

Stereotaxic surgery. Three weeks after ovariectomy, the animals were subjected to stereotaxic surgery to occlude the left middle cerebral artery (MCAo) as reported by Selvamani and Sohrabji (2008). MCA occlusion was induced by microinjecting $3 \mu \mathrm{l}$ of Endothelin-1 (American Peptide Company; $0.5 \mu \mathrm{l}$ in $1 \mu \mathrm{l}$ of PBS). Complete details of this procedure are described by Selvamani and Sohrabji (2008). This experimental stroke model results in a prolonged ischemia and gradual reperfusion, which lasts $\sim 7 \mathrm{~h}$ in the striatum and $16 \mathrm{~h}$ in the cortex (Biernaskie et al., 2001). Optical imaging studies using a small fluorescent probe $($ Cy5.5; $1 \mathrm{kDa}$ molecular weight) indicated that ET-1-induced vasoconstriction is clearly visible $5 \mathrm{~h}$ after ET-1, whereas reperfusion is apparent at $10 \mathrm{~h}$ in the midline (striatum) and is fully reestablished when imaged at $21 \mathrm{~h}$ after ET-1 (supplemental Fig. 1, available at www.jneurosci.org as supplemental material).

Intracerebroventricular infusions. (1) For concurrent IGF-1 or JB-1 administration, immediately after the ET-1 injection, a 28-gauge guide cannula (Alzet Brain Infusion kit II; Durect) was implanted in the lateral ventricle: intracerebroventricular coordinates: $-1.0 \mathrm{~mm}$ anterior posterior, $+1.4 \mathrm{~mm}$ medial lateral, $-3.5 \mathrm{~mm}$ relative to the dural surface (Paxinos et al., 1985), and cemented in place with loctite 454 (Durect). For intracerebroventricular infusions, Alzet osmotic minipumps (model $1007 \mathrm{D} ; 0.5 \mu \mathrm{l} / \mathrm{h}$ ) with a reservoir volume of $96 \pm 2 \mu \mathrm{l}$ was filled with vehicle [artificial CSF (aCSF)], intracerebroventricular IGF-1 (100 $\mu \mathrm{g} /$ $\mathrm{ml}$; total range, 9.4-9.8 $\mu \mathrm{g}$; Bachem), or JB-1 (20 $\mu \mathrm{g} / \mathrm{ml}$; total range, $1.88-1.96 \mu \mathrm{g}$; Bachem) and primed before implantation as recommended by the manufacturer. Osmotic minipumps were implanted subcutaneously over the latissimus dorsi muscles and connected via catheters to the infusion cannula in the lateral ventricle. Doses used for intracerebroventricular administration of IGF-1 were similar to those reported by Quesada and Micevych (2004). (2) For delayed IGF-1 administration, IGF-1 was administered $4 \mathrm{~h}$ after the ET-1 injection.

During surgery, the rats were maintained at $37^{\circ} \mathrm{C}$ throughout, and oxygen saturation and respiratory rate were constantly monitored using the Mouse Oximeter (STARR Life Sciences). Acceptable parameters for oxygen saturation and respiratory rate were $>85 \%$ and 50 brpm, respectively (for mean \pm SD for each treatment group, see supplemental Table 1, available at www.jneurosci.org as supplemental material). At termination, the brain was rapidly removed and processed for 2,3,5-triphenyltetrazolium chloride (TTC) staining and biochemical analysis. The uterus was also removed, cleaned, and weighed.

Infarct volume. Brain slices ( $2 \mathrm{~mm}$ thick) between -2.00 and +4.00 $\mathrm{mm}$ from bregma were incubated in a $2 \%$ TTC solution at $37^{\circ} \mathrm{C}$ for 20 min and later photographed using a Nikon E950 digital camera attached to a dissecting microscope. Infarct volume was determined from digitized images using the Quantity One software package (Bio-Rad). Typically, three such slices were used for analysis. The area of the cortical and striatal infarct was measured separately in all slices as well as the contralateral hemispheres. Details of the volume determination are described by Selvamani and Sohrabji (2008). The volume of the infarct was normalized to the volume of the contralateral (nonoccluded) hemisphere. To ensure reliable and consistent detection of the infarct zone, images were digitally converted to black-and-white and magnified, and all traces were performed by the same author (A. Selvamani).

Vibrissae-elicited forelimb placement test. Stroke injury was assessed by the forelimb placing test, which was performed both before and after the MCAo as described by Woodlee et al. (2005) and Selvamani and Sohrabji (2008). Animals were subjected to same-side placing trials and crossmidline placing trials elicited by the ipsilesional and contralesional vibrissae. Detailed description of same-side and cross-midline placing tests, pretest and posttest sessions, and scoring during each test session are reported by Selvamani and Sohrabji (2008). Vibrissae-evoked forelimb placement revealed a significant loss of right paw placement in all animals poststroke, indicative of left-sided cortical-striatal infarction (supplemental Figs. 2-4, available at www.jneurosci.org as supplemental material).

Cytokine and prostanoid expression. Expression levels of a panel of inflammatory cytokine/chemokine were quantified using a rat cytokine/ chemokine panel (Milliplex MAP kit; Millipore). The Bio-Plex Suspension System was calibrated using CAL2 (High PMT; Bio-Plex Calibration kit) and standard/sample preparation was performed according to the manufacturer's directions. Filter plate was prewet with assay buffer and vacuum filtered before adding standard, control, or samples to the appropriate wells. Premixed beads were then added to each well and incubated overnight at $4^{\circ} \mathrm{C}$ with shaking. After two washes, $25 \mu \mathrm{l}$ of detection antibody was added to each well and incubated for $2 \mathrm{~h}$ at room temperature and then treated with streptavidin-phycoerythrin $(25 \mu \mathrm{l})$ to each well for $30 \mathrm{~min}$ at room temperature. The plate was then washed twice with wash buffer, and the beads were resuspended in $150 \mu$ l of BioReady assay buffer and read on the BioPlex Suspension System. Cytokines levels were normalized to total protein values. 
Prostaglandin $\mathrm{E}_{2}\left(\mathrm{PGE}_{2}\right)$ levels were measured using a commercial enzyme immunoassay kit (Cayman) per the manufacturer's instruction. Samples, standards, controls, prostaglandin $\mathrm{E}_{2} \mathrm{AChE}$ tracer, and prostaglan$\operatorname{din} \mathrm{E}_{2}$ monoclonal antibody were added to appropriate wells in a 96-well plate as stated in the kit protocol and incubated at $4^{\circ} \mathrm{C}$ overnight. After the wash, Ellman's reagent was added to each well, and the plates were read at $412 \mathrm{~nm}$ in a plate reader (Tecan). Sample measurements were interpolated from the standard curve and normalized to total protein values.

Protein extraction and Western blot analysis. Cell proteins from cortical tissue (core and penumbra) and striatal tissue from the left and right hemispheres were harvested in lysis buffer $(50 \mathrm{~mm}$ Tris, pH 7.4, $150 \mathrm{~mm} \mathrm{NaCl}$, $10 \%$ glycerol, $1 \mathrm{~mm}$ EGTA, $1 \mathrm{~mm} \mathrm{Na}$ orthovanadate, $\mathrm{pH} 10,5 \mu \mathrm{M} \mathrm{ZnCl}, 100 \mathrm{~mm}$

$\mathrm{NaF}, 10 \mu \mathrm{g} / \mathrm{ml}$ aprotinin, $1 \mu \mathrm{g} / \mathrm{ml}$ leupeptin, $1 \mathrm{~mm}$ phenylmethylsulfonyl fluoride in dimethylsulfoxide, $1 \%$ Triton X-100) and centrifuged at $20,000 \mathrm{rpm}$ for $30 \mathrm{~min}$. Supernatant was collected and stored at $-20^{\circ} \mathrm{C}$ until additional analysis. Protein concentrations were determined using the BCA protein assay kit (Pierce). Samples were size fractionated on $10 \%$ PAGE and transferred to Hybond-C membranes (GE Healthcare). Blots were blocked with $1 \times$ Tris-buffered saline containing $0.05 \%$ Tween 20 and 5\% nonfat dry milk. Subsequently, blots were probed for either estrogen receptor $\alpha(\mathrm{ER} \alpha)$ or extracellular signal-regulated kinase (ERK). Blots were incubated with primary [1:200; ER $\alpha$ (MC20); Santa Cruz; p-ERK; 1:200; Santa Cruz] and secondary antibodies (1:2000; goat anti-rabbit; Santa Cruz; goat anti-mouse; 1:2000; BD Biosciences Pharmingen) subjected to three washes in $1 \times$ Tween Tris-buffered saline buffer between the two incubations. The immunosignal was detected by $\mathrm{x}$-ray film (Bio-Rad) using chemiluminescence reagents (Renaissance; PerkinElmer Life and Analytical Sciences). Blots were stripped and reprobed for either tubulin or pan-ERK (1:200; Santa Cruz). Immunosignal was quantified using computer-assisted densitometric analysis (Quantity One; Bio-Rad). ER $\alpha$ immunosignal was normalized to tubulin, whereas phospho-ERK immunosignal was normalized to pan-ERK.

Immunoprecipitation. Cortical protein lysates $(300 \mu \mathrm{g})$ from left and right hemispheres were incubated with $\mathrm{ER} \alpha$ antibody (1:100) overnight on a nutator at $4^{\circ} \mathrm{C}$. Samples were then immunoprecipitated with sheep anti-rabbit IgG Dynabeads M280 (Invitrogen; Dynal) for $3 \mathrm{~h}$. After washes, the immunoprecipitate was size fractionated on 10\% PAGE and transferred to nylon membranes (Millipore). Blots were blocked with $1 \times$ Tris-buffered saline containing $0.05 \%$ Tween 20 and $5 \%$ nonfat dry milk. Subsequently, blots were incubated with IGF-1 receptor (IGF-1R) antibodies [1:200; IGF-1R (C-20); Santa Cruz] and secondary antibodies (1:2000; goat anti-rabbit; Santa Cruz), subjected to three washes in $1 \times$ Tween Tris-buffered saline buffer between the two incubations. In parallel experiments, cortical lysates were immunoprecipitated with IGF-1R antibody and later resolved on 10\% PAGE and probed with the ER $\alpha$ antibody. In each case, immunosignal was detected on $\mathrm{x}$-ray film (BioRad) using chemiluminescence reagents (Renaissance; PerkinElmer Life and Analytical Sciences).

Detection of oxidized proteins. The Oxyblot protein oxidation detection kit (Millipore) was used to detect and quantify oxidized proteins in cortical lysates. A total of $10 \mu \mathrm{l}$ aliquot of protein was denatured using $6 \%$ SDS and derivatized with $1 \times 2$,4-dinitrophenylhydrazine $(\mathrm{DNPH})$ at room temperature for $15 \mathrm{~min}$. After which, the samples were treated to a neutralization solution and reduced with 2-mercaptoethanol. Proteins were separated by $10 \%$ SDS-PAGE and transferred to a Hybond-C membrane (GE Healthcare). Blocking and dilution buffers for primary and secondary antibodies were prepared per the manufacturer's instructions. The 2,4-dinitrophenyl (DNP)-derived protein expression was normalized to $\alpha$-tubulin (1:2000; Sigma-Aldrich).

Statistics. Infarct volume was analyzed by two-way ANOVA (independent variables: plus/minus hormone, plus/minus IGF-1, or plus/minus JB-1) with planned comparisons. The effect of stroke injury on the forelimb placement test was analyzed by paired $t$ test (pre-MCAo and postMCAo). A three-way ANOVA was used for ERK activation, ER $\alpha$ expression, cytokines, and protein oxidation, with "hemisphere" as the repeated measure, and plus/minus hormone and plus/minus IGF-1 as independent variables. Statistical analysis was performed using the software package SPSS 13.0.

\section{Results}

\section{Estrogen treatment}

Hormone replacement was confirmed by uterine weights, which is a cumulative indicator of estrogen stimulation. Uterine weights were similar in ovariectomized young adult (3-4 months of age) $(0.15 \pm 0.024 \mathrm{~g})$, mature adult (5-7 months of age) $(0.17 \pm 0.016$ $\mathrm{g})$, and reproductive senescent (9-11 months of age) (0.18 \pm $0.03 \mathrm{~g}$ ) females. Three weeks of estrogen treatment increased uterine weights in all groups (young adult, $0.49 \pm 0.09 \mathrm{~g}$; mature adult, $0.51 \pm 0.086 \mathrm{~g}$; reproductive senescent, $0.52 \pm 0.098 \mathrm{~g}$ ). There were no differences in uterine weights in ovariectomized young, mature, and senescent females. Similarly, estrogen treatment had comparable effects at all ages.

\section{Local and circulating levels of IGF-1}

Plasma samples were obtained from ovariectomized young adult (3-4 months), mature adults (5-7 months), and reproductive senescent females (9-11 months) that were ovariectomized and replaced with an estrogen or placebo pellet. As shown in Figure $1 A$, IGF-1 was detected in plasma from all reproductive ages; however, there was a statistically significant decline in the level of this peptide with reproductive age $\left(F_{(2,21)}=24.83 ; p<0.05\right)$. Furthermore, IGF-1 levels were also significantly suppressed in estrogen-treated animals $\left(F_{(1,21)}=5.26 ; p<0.05\right)$, at each age group. Specifically, estrogen reduced IGF-1 levels by $22 \%$ in young adults, $14 \%$ in mature adults, and $30 \%$ in reproductive senescent females. Consequently, reproductive senescent females treated with estrogen had the lowest circulating levels of IGF-1. Post hoc analysis of the treatment groups indicates that IGF-1 levels in the estrogen-treated senescent females are significantly lower than those in estrogen-treated young adults and estrogentreated mature adults ( $p<0.05$, in both cases). Local IGF-1 levels were measured from the micropunches of cortical tissue obtained from the cortex of mature and senescent females. Similar to plasma levels, cortical IGF-1 levels were $\sim 40 \%$ lower in reproductive senescent females compared with mature adult females (Fig. $1 B$ ). Thus, local and circulating levels of IGF-1 were suppressed in older acyclic females. 
A

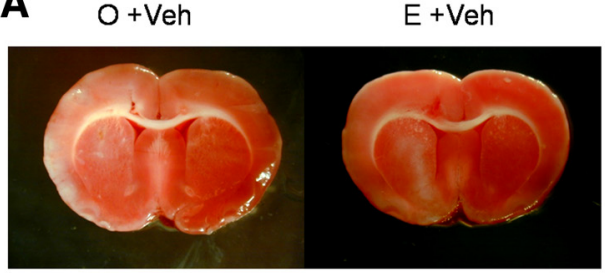

$\mathrm{O}+\mathrm{JB}-1$

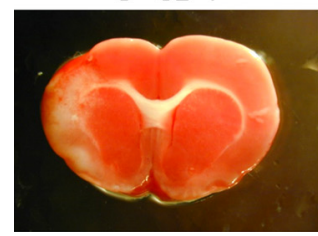

$E+J B-1$

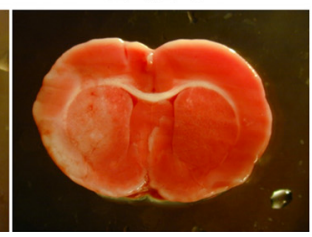

B

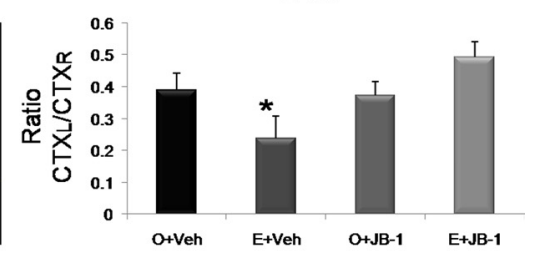

C

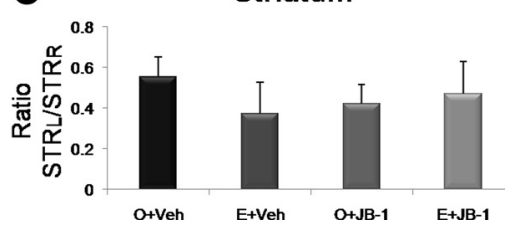

Figure 2. Effects of estrogen and concurrent JB-1 treatment on infarct size in mature adult females. MCA0 induced by ET-1 injections resulted in cortical and striatal lesions as indicated by TTC-stained sections $(\boldsymbol{A})$. The volume of the cortical infarct was significantly reduced in the estrogen-treated mature adult females (E) compared with the control-replaced females $(0)$, whereas JB-1 treatment reversed this effect. Neither estrogen nor JB-1 affected striatal infarct volume. Histogram depicts mean \pm SEM of cortical $(\boldsymbol{B})$ and striatal $(\boldsymbol{C})$ infarct volume as a ratio of the contralateral cortex and striatum, respectively. $n=4-6$ in each group; ${ }^{*} p<0.05$.

A

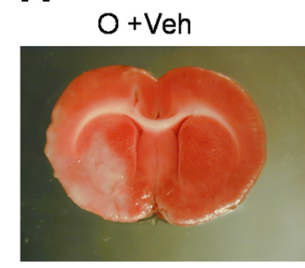

O+IGF-1

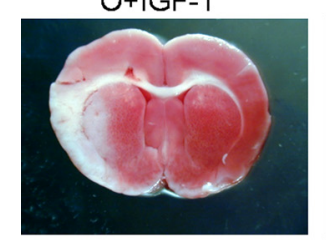

B

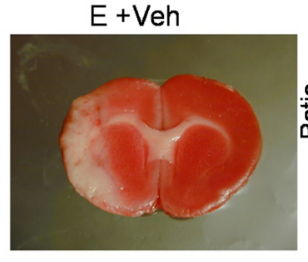

$E+\mid G F-1$

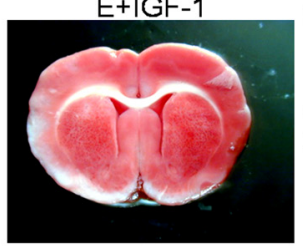

C
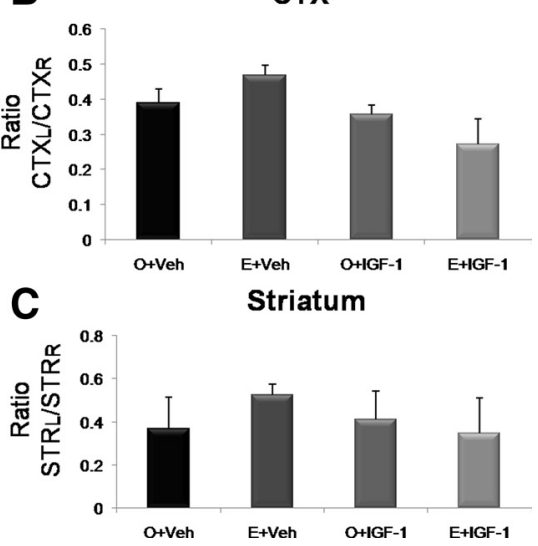

Figure 3. Effects of estrogen and concurrent IGF-1 treatment on infarct size in reproductive senescent females. MCAo induced by ET-1 injections resulted in cortical and striatal infarcts, as indicated by the TTC staining $(\boldsymbol{A})$. The volume of the cortical infarct was significantly greater in the estrogen-treated reproductive senescent females (E) compared with the control-replaced females ( 0 ). Intracerebroventricular infusion of IGF-1 concurrent with the onset of ischemia attenuated infarct size ( $a$, main effect of IGF-1, $p<0.05$ ). Planned comparisons indicate that cortical infarct size is reduced in the $E+I G F-1$ group compared with the $E+V$ eh, but is equivalent to the $0+V$ eh group. Neither estrogen nor IGF-1 had any effect on striatal infarct volume. Histogram depicts mean \pm SEM of cortical (B) and striatal (C) infarct volume as a ratio of the contralateral cortex and striatum, respectively. $n=4-6$ in each group.

\section{Effect of inhibition of IGF-1 signaling on ischemia infarct volume in mature adult females}

Adult multiparous females with normal estrus cycles (see Materials and Methods) were ovariectomized and replaced with estradiol or a placebo pellet. Three weeks later, animals were subject to MCA ischemic stroke induced by endothelin- 1 and immediately infused with the IGF-1 receptor antagonist JB-1 directed to the lateral ventricles (intracerebroventricularly). Seven days later, all animals were terminated, and their brains were removed and assessed for cell death by TTC staining (Fig. 2A). As shown in Figure $2 B$, cortical infarct volume was modified by a complex interaction of estrogen and the IGF-1 inhibitor, JB-1 $\left(F_{(1,14)}=\right.$ 5.794; $p<0.05$; interaction effect). Similar to previous data, estrogen treatment to ovariectomized mature adult females reduced $(39 \%)$ the volume of the cortical infarct. However, JB-1 treatment completely attenuated the neuroprotective effects of estrogen in this group, so that infarct volumes in this group were similar to non-estrogen-treated controls. Notably, JB-1 did not affect cortical infarct volume in animals that were not treated with estrogen (Fig. 2). Furthermore, JB-1 had no effect on the striatal infarct (Fig. 2) (overall ANOVA, $F_{(3,14)}=$ $0.751 ; p>0.05)$.

\section{Effect of IGF-1 replacement on ischemic infarct volume in reproductive senescent females} Reproductive senescent females (multiparous, acyclic females that were in constant diestrus) were ovariectomized and replaced with estrogen or control pellets and subject to ET-1-induced MCAo. IGF-1 was infused intracerebroventricularly either concurrent with the MCAo or delayed $4 \mathrm{~h}$ after MCAo.

\section{Concurrent IGF-1 treatment}

Concurrent IGF-1 treatment had a significant effect on cortical infarct size $\left(F_{(1,14)}\right.$ $=6.028533 ; p<0.05)$. As reported previously, cortical infarct volume was significantly worse in estrogen-treated animals compared with untreated ovariectomized animals (Fig. 3). Planned statistical comparisons indicate that IGF-1 infusion to estrogen-treated females reduced cortical infarct volume compared with the group treated with estrogen alone $(p<0.05)$ but was equivalent to the baseline group (no estrogen, no IGF-1) ( $p>0.05)$. IGF-1 had no additional effect on infarct volume in groups deprived of estrogen treatment. Neither IGF-1 nor estrogen treatment affected the striatal infarct (Fig. $3 B$ ) (overall ANOVA, $\left.F_{(3,14)}=1.72 ; p>0.05\right)$.

\section{Delayed IGF-1 treatment}

The next study tested the efficacy of delayed IGF-1 treatment on infarct volume. Reproductive senescent animals were prepared as before and infused with IGF-1, $4 \mathrm{~h}$ after the MCAo was initiated. Delayed IGF-1 treatment had a remarkable neuroprotective effect on cortical infarct volume $\left(F_{(3,18)}=10.125 ; p<0.05\right)$ and a significant interaction effect of estrogen and IGF-1 $\left(F_{(3,18)}=13.09 ; p<\right.$ 0.05). Thus, although IGF-1 had an overall effect on lowering infarct volume, this effect was mainly driven by the interaction with estrogen and IGF-1. Although estrogen replacement alone to senescent females increased infarct volume compared with untreated controls, IGF-1 treatment to this group not only reversed the toxic effects of estrogen but also reduced cortical infarct volume compared with baseline (untreated controls). As before, IGF-1 did not affect the cortical infarct volume in the untreated ovariectomized group of animals. IGF-1 and estrogen also did not affect striatal infarct volume (Fig. 4) (overall ANOVA, $\left.F_{(3,18)}=0.696 ; p>0.05\right)$.

In view of the neuroprotective effects of combined estrogen/ delayed IGF- 1 treatment to senescent females at $7 \mathrm{~d}$ poststroke, the next series of experiments determined the early biochemical 
effects of combined estrogen/delayed IGF-1 treatment on ischemic tissue $(24 \mathrm{~h}$ after MCAo). In this study, local cortical and striatal levels of IGF-1 were first measured to determine whether IGF-1 infusion increased local levels of the peptide. Cortical levels of IGF-1 were significantly elevated by IGF-1 infusion (1.6-fold; $p<$ 0.05) (Fig. 5A); however, intracerebroventricular infusion of IGF-1 did not increase striatal IGF-1 levels. Whether this is attributable to the location of the cannula (which favored cortical rather than striatal distribution of the peptide) or attributable to poor sequestration of the peptide in the striatum, these data are consistent with the absence of IGF-1-dependent changes in striatal infarct volume seen in the above studies.

Overall, IGF-1 levels were $~ 50 \%$ lower in the striatum compared with the cortex. As shown in Figure 5B, cortical IGF-1 levels were increased by $60 \%$ in the ischemic hemisphere $\left(F_{(1,6)}=31.46 ; p<0.05\right.$; repeated measure) compared with the nonischemic side. Estrogen treatment significantly decreased IGF-1 levels in the ischemic and nonischemic cortex $\left(F_{(1,6)}=\right.$ 10.09; $p<0.05)$. Striatal IGF-1 levels were also higher in the ischemic hemisphere $(27 \%)$, although this was not statistically significant $\left(F_{(1,6)}=4.58 ; p=\right.$ 0.076 ; repeated measure), and estrogen did not alter IGF-1 levels in this region.

\section{ERK activation in the ischemic site}

ERK signaling is associated with oxidative stress and cell death (Murray et al., 1998; Poddar and Paul, 2009) and suppression of ischemia-induced ERK activation is associated with reduced infarct volumes (Wakade et al., 2008). Cortical tissue from reproductive senescent females subject to MCAo was harvested at $24 \mathrm{~h}$ and sizefractionated by SDS-PAGE and probed for phospho-ERK and pan (total)-ERK. As expected, ERK-1 activation was enhanced twofold to fourfold in the ischemic cortex compared with the nonischemic cortex in most groups (Fig. 6). However, estrogen plus IGF-1 treatment completely suppressed ERK-1 phosphorylation in the ischemic cortex and was no different from the nonischemic hemisphere $(F=5.989$; $p<0.05$; interaction hemisphere by IGF-1 by estrogen). The early suppression of ERK-1 phosphorylation is consistent with the neuroprotective effect of estrogen and IGF-1 seen in this group at $7 \mathrm{~d}$ after stroke.

\section{Cytokine expression in the ischemic site}

Ischemia is associated with neuroinflammation resulting from activation of local microglia and astrocytes as well as infiltration of leukocytes because of breakdown of the blood-brain barrier. In the next analysis, cortical lysates from the ischemic and nonischemic hemisphere from the " 24 h delayed IGF-1" study were also assayed by multiplex ELISA for a panel of cytokines. A large
B CTX ${ }^{a}$
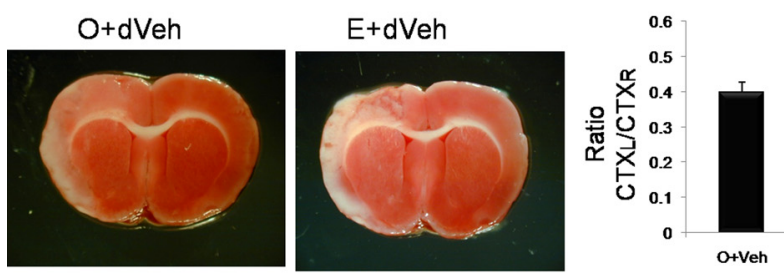

$E+d \mid G F-1$

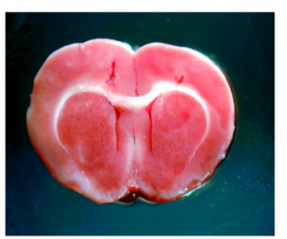

C
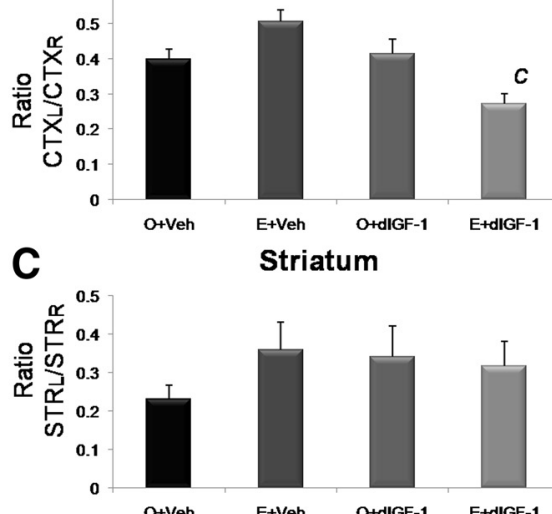

Striatum

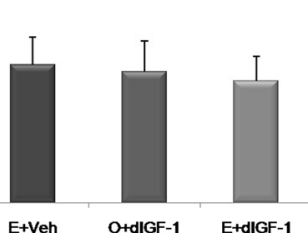

Figure 4. Effect of estrogen and delayed IGF-1 treatment on infarct size in reproductive senescent females. $\boldsymbol{A}$, TTC-stained sections from the brain of animals subject to ischemic stroke induced by ET-1 injections. Cortical infarct volume was significantly greater in estrogen-treated reproductive senescent females (E) compared with the control-replaced females (0). Intracerebrovenwastion effect of $\mathrm{E}+\mathrm{IGF}-1$ ( $c$, interaction effect, $p<0.05$ ). Planned comparisons indicate that the cortica infarct volume was significantly reduced in the $\mathrm{E}+\mathrm{IGF}-1$ group compared with all other groups including $\mathrm{E}+\mathrm{Veh}$ and the $0+V$ eh No effect of estrogen or delayed IGF-1 was seen on striatal infarct volume. $\boldsymbol{B}, \boldsymbol{C}$, Histogram depicts mean \pm SEM of cortical $(\boldsymbol{B})$ and

A

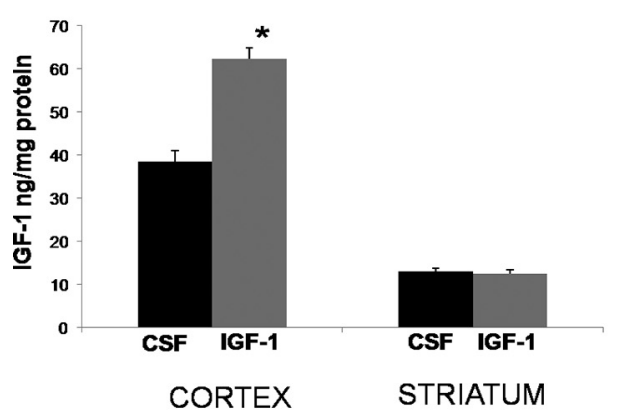

Figure 5. IGF-1 expression in the cortex and striatum of reproductive senescent females. A, IGF-1 was infused $4 \mathrm{~h}$ after the onset of ischemia and was measured $24 \mathrm{~h}$ later. Intracerebroventricular infusions of IGF-1 significantly increased peptide accumulation in he cortex, but not in the striatum. $\boldsymbol{B}$, Endogenous levels of IGF-1 levels were increased in the ischemic cortex compared with the had lower levels of IGF-1 ( $b$, main effect of estrogen, $p<0.05$ ). No significant differences were observed in the striatum. ${ }^{*} p<$ 0.05 . Error bars indicate SEM.

number of cytokines are elevated in the ischemic cortex compared with the contralateral hemisphere (supplemental Table 2, available at www.jneurosci.org as supplemental material; main effect of "hemisphere," indicated by upward or downward pointing arrow). Virtually none of these were regulated by estrogen and/or IGF-1 at $24 \mathrm{~h}$ after ischemia. Furthermore, only one inflammatory mediator was regulated by an interaction of IGF-1/ estrogen, $\mathrm{PGE}_{2}$. $\mathrm{PGE}_{2}$, which is synthesized enzymatically from arachidonic acid, is reportedly elevated after ischemia and neural injury. As shown in Figure 7 , at $24 \mathrm{~h}$ after ischemia, $\mathrm{PGE}_{2}$ was modestly elevated in the ischemic hemisphere $\left(F_{(1,14)}=6.047\right.$; main effect of hemisphere; repeated measure; $p<0.05)$. Furthermore, animals that received estrogen plus IGF-1 had the highest levels of $\mathrm{PGE}_{2}$ at this early time point $\left(F_{(1,14)}=4.86\right.$; interaction effect of estrogen and IGF-1; $p<0.05)$. At $7 \mathrm{~d}$ after ischemia, $\mathrm{PGE}_{2}$ was elevated in the ischemic hemisphere in all groups to a similar extent $\left(F_{(1,14)}=165.64\right.$; main effect of hemisphere; $p<$ 


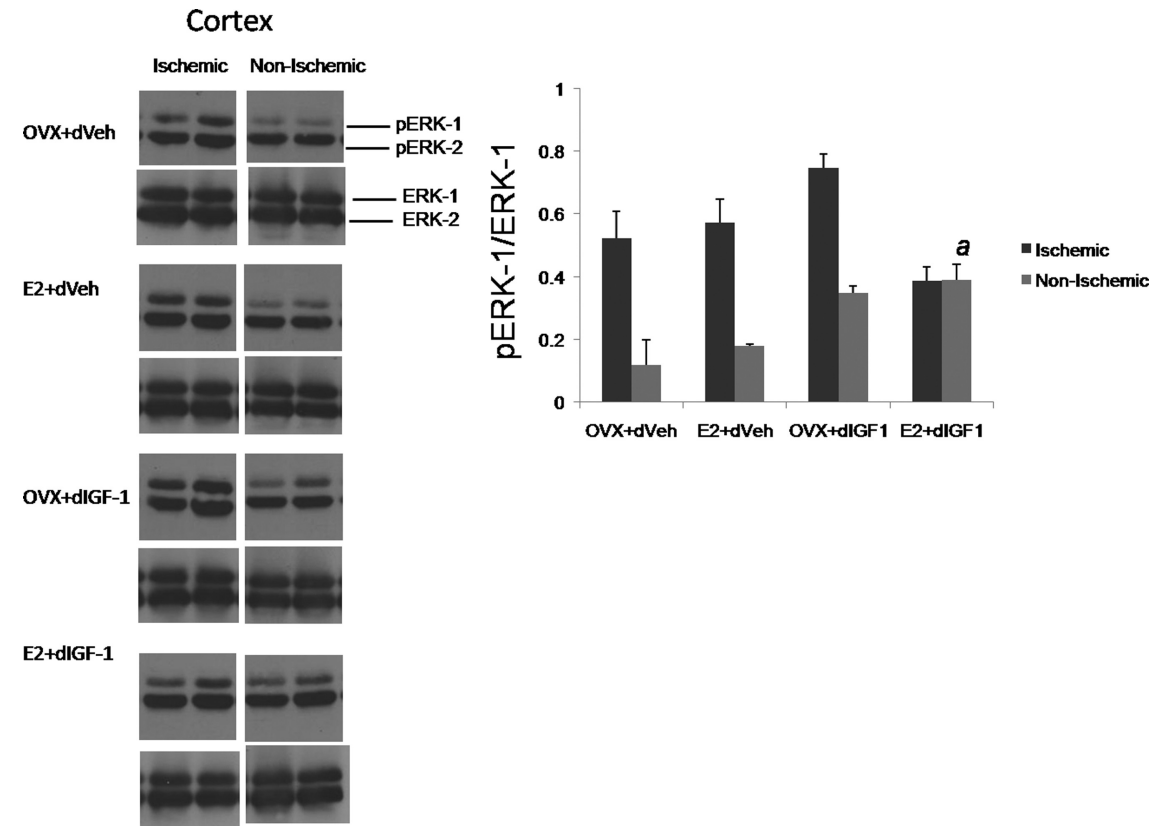

Figure 6. Western blot analysis of phospho- and pan-ERK expression in cortical lysates from the ischemic and nonischemic hemispheres of reproductive senescent females. Although pERK-1 expression (normalized to ERK-1) was elevated in the ischemic hemisphere in most treatment groups, estrogen treatment combined with delayed IGF-1 infusion suppressed ischemia-induced ERK-1 activation ( $a$, interaction effect of hemisphere, estrogen, IGF-1). $n=3-4$ per group. Error bars indicate SEM.
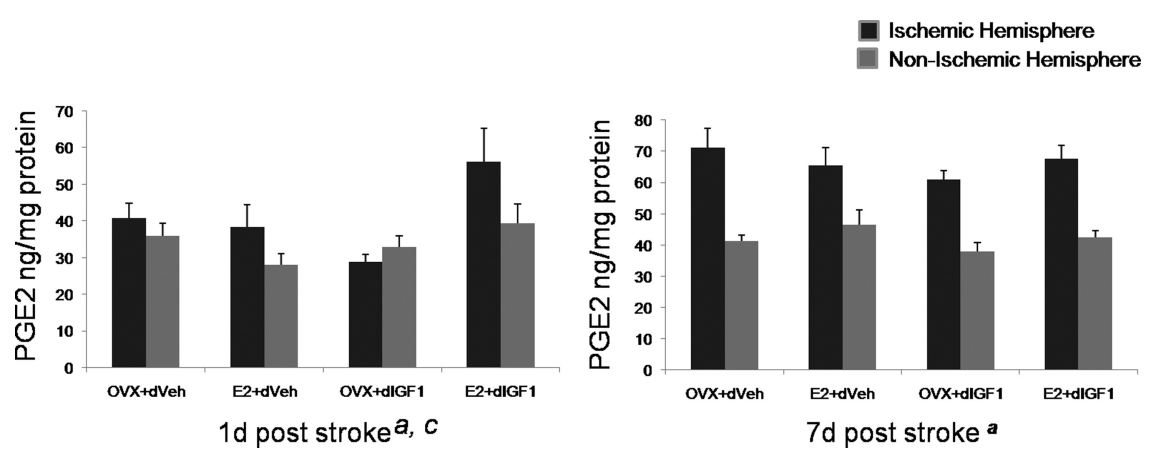

Figure 7. $P \mathrm{PE}_{2}$ expression in the ischemic and nonischemic cortex. $\mathrm{PGE}_{2}$ levels were measured by ELISA and normalized to total protein. At $24 \mathrm{~h}$ after MCAo, PGE, levels were modestly elevated in the ischemic cortex ( $a$, main effect of hemisphere, repeated measure, $p<0.05$ ). The levels of $\mathrm{PGE}_{2}$ were highest in the group that received estrogen and IGF-1 ( $c$, interaction effect of $\mathrm{E}+\mathrm{IGF}-1, p<0.05$ ). At $7 \mathrm{~d}$ after MCAo, PGE 2 levels were elevated in the ischemic cortex of all groups ( $p<0.05$, main effect of hemisphere, repeated measure) to a similar extent. $n=4-6$ per group. Error bars indicate SEM.

$0.05)$, indicating that estrogen and IGF-1 promotes an early elevation of this prostanoid.

\section{Protein oxidation}

Oxidation of carbonyl groups is an indicator of oxidative stress on proteins and is correlated with cell death (Niebrój-Dobosz et al., 2004; Sultana et al., 2004). Carbonyl groups on proteins that react with DNPH to form DNP were examined by immunoblotting. 2,4-DNP-modified proteins were seen in all groups (Fig. 8), but the intensity of the immunosignal (normalized to tubulin) was significantly reduced in the groups exposed to IGF-1 $\left(F_{(1,11)}\right.$ $=15.49 ; p<0.05)$, indicative of lower protein oxidation in these groups.

\section{Immunoprecipitation of estrogen and IGF receptors}

Since the previous studies indicate that estrogen and IGF-1 interact to regulate crucial measures such as infarct volume, ERK-1 phosphorylation, and $\mathrm{PGE}_{2}$ expression in the ischemic cortex, the next studies determined estrogen receptor expression in the ischemic cortex and its interaction with IGF-1R, the tyrosine kinase receptor that transduces the actions of IGF-1. $\mathrm{ER} \alpha$, a $68 \mathrm{kDa}$ protein that has been implicated in the neuroprotective/neuroinflammatory actions of estrogen (Dubal et al., 2001; Vegeto et al., 2003), was examined by Western blot analysis. As shown in Figure $9 A$, both ischemic and nonischemic cortices expressed $\mathrm{ER} \alpha$. However, $\mathrm{ER} \alpha$ expression was significantly reduced in the ischemic cortex, compared with the contralateral hemisphere, in groups that received aCSF infusion. In groups infused with IGF-1, ER $\alpha$ levels were no different from the contralateral hemisphere (interaction effect, hemisphere by IGF-1 treatment; $\left.F_{(1,10)}=7.02 ; p<0.05\right)$, indicating that the peptide serves to maintain estrogen responsiveness in infarcted tissue.

Immunoprecipitation of ER $\alpha / \mathrm{IGF}-1 \mathrm{R}$ complexes from cortical tissue obtained from ischemic and nonischemic hemispheres were assessed using both $\operatorname{ER} \alpha$ and IGF-1R antibodies as a probe (Fig. 9B). $\mathrm{ER} \alpha$-precipitated lysates probed for IGF-1R indicated a $78 \mathrm{kDa}$ band consistent with the IGF-1Rb segment. Similarly, cortical lysates immunoprecipitated with IGF-1R probed for ER $\alpha$ revealed an expected $68 \mathrm{kDa}$ band, indicating that $\mathrm{ER} \alpha$ dimerizes with IGF-1R. Immunoprecipitation of IGF-1R and ER $\alpha$ was seen in all treatment groups, and Figure $9 B$ shows expression of IGF-1R complexed to $\mathrm{ER} \alpha$ in the reproductive senescent group that received both estrogen and IGF-1 infusion.

\section{Discussion}

The present data demonstrate, for the first time, that the decline in the effectiveness of estrogen in the aging brain is associated with declining levels of IGF-1. Similar to humans (Waters et al., 2003; Denti et al., 2004), circulating IGF-1 levels decrease with age and are further suppressed in estrogen-replaced rats. In older acyclic females in which constitutive IGF-1 levels are low, compared with all other groups, exogenous replacement of IGF-1 attenuates the neurotoxic effects of the steroid hormone. In fact, delaying IGF-1 treatment for a few hours after the onset of ischemia completely reverses the neurotoxic effects of estrogen, resulting in reduced protein oxidation and suppression of pERK-1 at $24 \mathrm{~h}$ with reduced infarct volume at $7 \mathrm{~d}$ after stroke.

Although both concurrent and delayed IGF-1 attenuate the toxic effects of estrogen on infarct in older females, delayed IGF-1 is paradoxically more effective. Although not tested in the current studies, we hypothesize that concurrent IGF-1 delivery attenuates the development of compensatory poststroke cellular events. After ischemia, several cell death and cell-protective responses are generated in brain tissue, and the eventual size and severity of the 
infarct reflect the balance between these opposing cellular processes. For example, inflammation is a critical postischemic event, and IGF-1 is reported to promote T-cell maturation and delay apoptotic cell death of neutrophils (Himpe et al., 2008; Law et al., 2008), which is consistent with its growth-promoting actions but may create a less favorable environment for neurons postischemia. Thus, early IGF-1 treatment may hinder the development of a full neuroprotective effect.

Although the MCAo results in a cortical-striatal infarction, all our treatment effects (estrogen or IGF-1) are restricted to the cortical infarction. Striatal infarct volume is resistant to both estrogen and IGF-1 treatment, during the time frame of this study (7 d). This lack of improvement in the striatal infarct is consistent with the lack of improvement noted in the vibrissaeevoked forelimb placement task, since most recovery-of-function tasks involve a motor response. A related possibility is that the time frame of these studies is too short to detect functional recovery from stroke. For example, the "cross-midline" version of this task reportedly recovers in $28 \mathrm{~d}$, whereas the "same-side" version of this test remains impaired 128 d later (Woodlee et al., 2005). However, since behavioral improvement is almost always associated with recovery and reduced neuronal loss, the mechanisms underlying cortical neuroprotection described here provide a crucial insight into the response of the aging brain to stroke.

The reproductive senescent female rat mimics salient aspects of the postmenopausal human female, namely decreased reproductive capacity and diminished availability of ovarian hormones (estrapause). In this model, estrogen replacement is proinflammatory (Johnson and Sohrabji, 2005) and neurotoxic in stroke and excitotoxic inflammation models (Nordell et al., 2003; Selvamani and Sohrabji, 2008). Currently, the effect of estrogen treatment on ischemic injury in older females is controversial, with some studies indicating a beneficial effect (Alkayed et al., 2000; Dubal and Wise, 2001; Toung et al., 2004) and others, a neurotoxic effect (Selvamani and Sohrabji, 2008). These differences may be attributable to the animal species (rat vs mice), the determination of estrus acyclicity, as well as the nature of the ischemic insult itself. The ubiquitously used suture model, for example, in which a nylon suture is used to occlude the MCA, results in a rapid ischemia and a rapid reperfusion, whereas the vasoconstrictive (endothelin-1) stroke model causes a gradual ischemia and a gradual reperfusion. Hence the rate of infarct development and its pathophysiology may markedly vary between the two models, and this difference may crucially predict whether estrogen exerts protective or nonprotective actions.

Although the fundamental event in menopause is the "built-in obsolesence" (Mason 1976) of the ovary, other endocrine glands

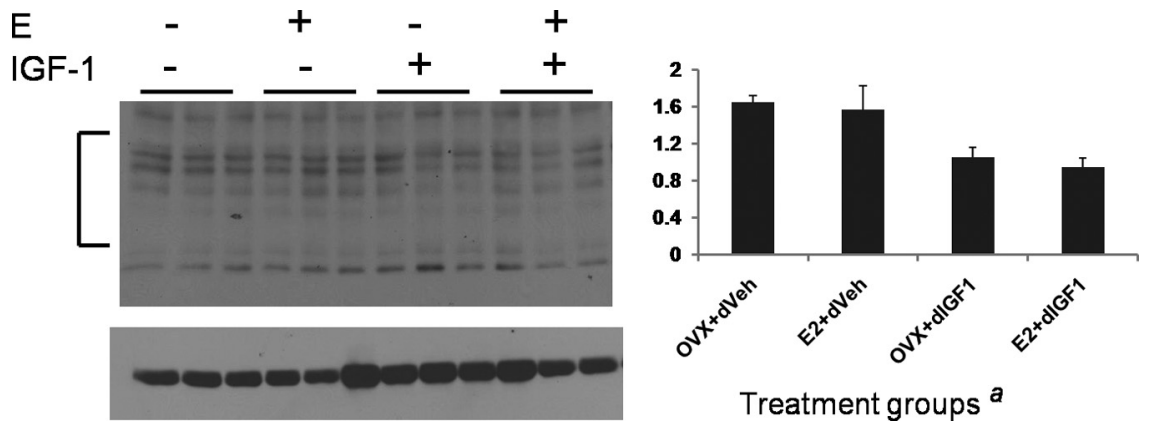

Figure 8. Western blot analysis of 2,4-DNP-modified proteins in ischemic cortical lysates from senescent animals treated with estrogen or control pellet and later treated intracerebroventricularly with either IGF-1 or vehicle $4 \mathrm{~h}$ after ischemia. Proteins were derivatized by incubating tissue lysates with 2,4-dinitrophenylhydrazine. Immunosignal for 2,4-DNP proteins normalized to a loading control (tubulin) was significantly decreased in groups that received IGF-1 infusion ( $a$, main effect of IGF-1, $p<0.05$ ). The bracket indicates the region in each lane that was quantitated by densitometry. $n=3$ per group. Error bars indicate SEM.
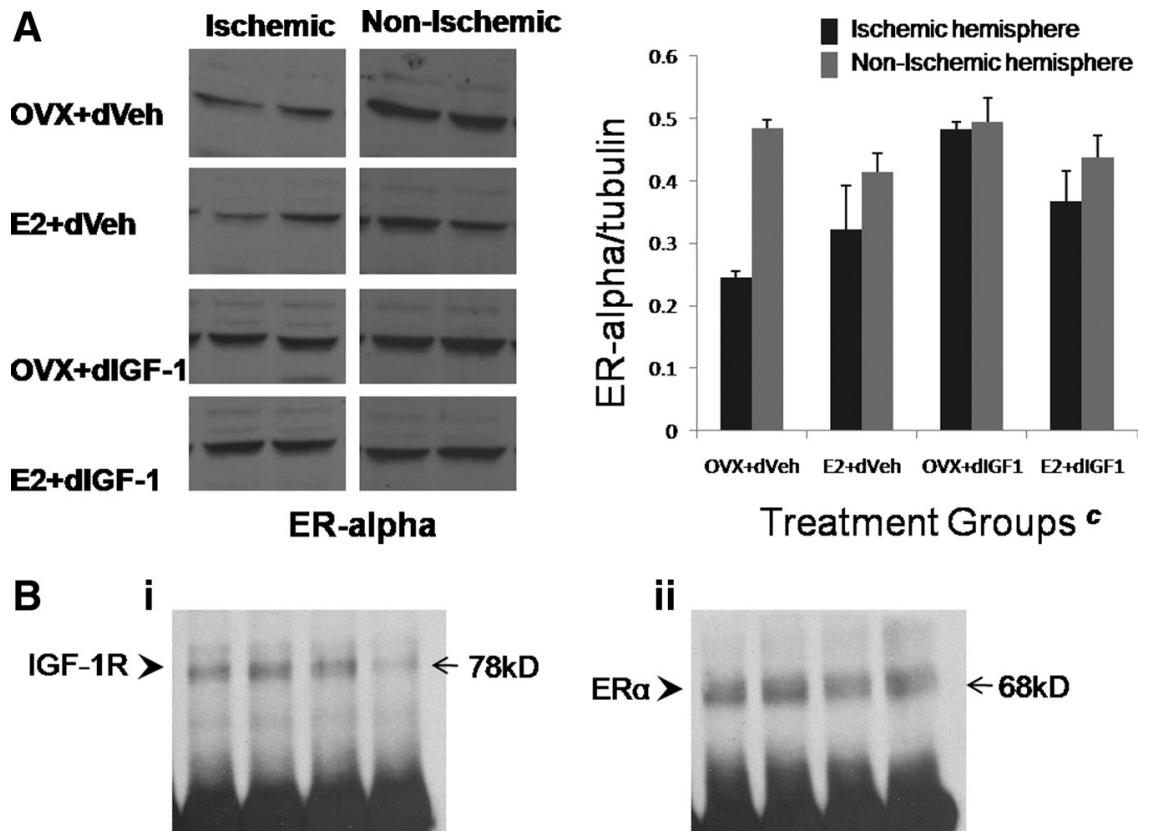

Figure 9. ER $\alpha$ expression and immunoprecipitation with IGF-1R in the cortex of reproductive senescent females. $A$, Western blot assays showing ER $\alpha$ expression in both the ischemic and nonischemic cortex. In the nonischemic cortex, ER $\alpha$ expression, normalized to tubulin, was similar in all groups. In the ischemic hemisphere, ER $\alpha$ expression was significantly higher in groups that were seen in all treatments; shown here are representative samples from the reproductive senescent animals treated with an estrogen pellet and intracerebroventricular infusion of IGF-1.

are also affected by age and declining stimulation from ovarian hormones. The GH (growth hormone)/IGF-1 axis also declines with age ("somatopause"), causing reductions in lean body mass, bone mass, and immune function. Aging and estrogen reduces the levels of circulating IGF-1 in young and middle-aged females (Böttner and Wuttke, 2006), and although this phenomenon increases longevity (Bartke et al., 2003; Brown-Borg, 2007), the age-related decline in IGF-1 may be deleterious for the injured brain. Exogenous IGF-1 reduces ischemic injury in many species (Gluckman et al., 1992; Lee and Bondy, 1993; Johnston et al., 1996; Guan et al., 2001), stimulates stroke-induced neurogenesis (Yan et al., 2006), and promotes neuronal survival, neuronal myelination, and angiogenesis (Wang et al., 2000; Smith, 2005). Similarly, estrogen is also known to decrease cell death after isch- 
emia in rats (Simpkins et al., 1997; Dubal et al., 1998; Rusa et al., 1999), mice (Sawada et al., 2000), and gerbils (Jover et al., 2002). Thus, in young adult animals, estrogen and IGF-1 are independently neuroprotective.

Garcia-Segura and colleagues (Garcia-Segura et al., 2001; Mendez et al., 2005; Torres Aleman, 2005) have shown that IGF-1 and estrogen also act cooperatively to prevent neuronal loss in neurodegenerative disease models. Estrogen and IGF-1 receptors are colocalized in neuronal and glial populations (CardonaGómez et al., 2000; Garcia-Segura et al., 2000; Quesada et al., 2007), promote the survival and differentiation of the same groups of neurons, and cooperatively modulate prosurvival signaling pathways (Cardona-Gómez et al., 2002). Furthermore, IGF-1-dependent neuronal differentiation and survival require estrogen receptors, and estradiol neuroprotection requires ongoing IGF-1 signaling (Garcia-Segura et al., 2006). Intriguingly, inhibiting the IGF-1 receptor with JB-1 attenuates the neuroprotective effects of both estrogen and IGF-1 (Quesada and Micevych, 2004). Our data uncover a unique interactive role for IGF-1 and estrogen in the aging brain, in which IGF-1 supplementation is only neuroprotective in animals that are replaced with estrogen. Furthermore, IGF-1 alone promotes specific protective actions, such as reducing protein oxidation, although, in the present model, this does not result in a full neuroprotective effect. IGF-1 stabilizes the ischemia-induced loss of ER $\alpha$ expression, indicating that IGF-1 may provide a substrate to enhance $\mathrm{ER} \alpha / \mathrm{IGF}-1 \mathrm{R}$ interactions. If estrogen and IGF-1 synergy is critical for neuroprotection, then the combination of advanced age coupled with estrogen treatment places the postmenopausal female and the reproductive senescent rat at risk for more severe cell loss after stroke.

The neuroprotective actions of IGF-1 are principally transduced by the receptor tyrosine kinase IGF-1R, whereas ER $\alpha$ is the estrogen receptor that mediates neuroprotection and neuroinflammation (Dubal et al., 2001; Vegeto et al., 2003). In vivo, estradiol treatment transiently increases the association between brain IGF-1R and ER- $\alpha$ (Mendez et al., 2003), whereas brain injury, as indicated in this study, prolongs the formation of ER$\alpha /$ IGF-1R dimers. ER $\alpha /$ IGF-1R dimerization most likely occurs at the plasma membrane, which strategically positions these receptors to exploit several signaling molecules. Both estrogen and IGF-1 receptors activate the MAP (mitogen-activated protein) kinases, a signaling platform responsive to a broad range of stimuli including cell proliferation, apoptosis, cell differentiation, and gene regulation. Oxidative stress, caused by ischemia, induces ERK phosphorylation (Namura et al., 2001), whereas suppression of ERK reduces cell death in vivo and in vitro (Murray et al., 1998; Williams et al., 1998; Noshita et al., 2002; Wang et al., 2003). Tamoxifen, which binds $\mathrm{ER} \alpha$, reduces ischemic infarction by a mechanism involving the suppression of ERK activation (Wakade et al., 2008), although estradiol has been shown to reduce cell death by activating ERK/MAPK (mitogen-activated protein kinase) (Jover-Mengual et al., 2007). In the present study, IGF-1 infusion to estrogen-treated older rats reduces both ERK-1 activation and infarct size.

Although the specific neuroprotective mechanism initiated by estrogen/IGF-1 remains to be elucidated, one possibility is the suppression of stroke-induced neuroinflammation. Of the large number of inflammatory proteins elevated by ischemia, only $\mathrm{PGE}_{2}$ was specifically elevated by the combination of estrogen and IGF-1. PGE 2 belongs to a family of lipid-signaling molecules implicated in neuronal injury and inflammation, although recent evidence indicates that $\mathrm{PGE}_{2}$ promotes neuronal survival when bound to specific receptor subtypes. Specifically, the $\mathrm{EP}_{2}$ receptor promotes cell survival in permanent ischemia (Liu et al., 2005) and ischemia/reperfusion (McCullough et al., 2004) models. Neuronal $\mathrm{EP}_{2}$ expression is rapidly reduced in the ischemic core but is retained in periinfarct neurons and induced in endothelial cells, in which it remains elevated even 24 h later (Li et al., 2008). If this early increase in $\mathrm{EP}_{2}$ receptors in periinfarct neurons and endothelial cells is a general feature of ischemic injury, then the rapid elevation of $\mathrm{PGE}_{2}$ in the IGF-1/estrogen-treated animals seen in this study may be critical for promoting cell survival.

The present studies emphasize the convergence of multiple endocrine changes in the aging animal and their impact on the pathophysiology of stroke and ischemic injury. A recent study by Liu et al. (2009) clearly demonstrates that age is a crucial factor in the severity of stroke, and the present study points to a substrate (IGF-1) that may underlie this age-related susceptibility to increased tissue damage. The present study also offers the exciting possibility of a therapeutic intervention to reduce the extent of tissue damage after stroke in postmenopausal females, a population both likely to use estrogen therapy and at greater risk for stroke. The fact that IGF-1 treatment can be neuroprotective even when delivered after the onset of ischemia indicates a broad window of therapeutic opportunity for this compound.

\section{References}

Alkayed NJ, Murphy SJ, Traystman RJ, Hurn PD, Miller VM (2000) Neuroprotective effects of female gonadal steroids in reproductively senescent female rats. Stroke 31:161-168.

Bartke A, Chandrashekar V, Dominici F, Turyn D, Kinney B, Steger R, Kopchick JJ (2003) Insulin-like growth factor 1 (IGF-1) and aging: controversies and new insights. Biogerontology 4:1-8.

Biernaskie J, Corbett D, Peeling J, Wells J, Lei H (2001) A serial MR study of cerebral blood flow changes and lesion development following endothelin-1induced ischemia in rats. Magn Reson Med 46:827-830.

Böttner M, Wuttke W (2006) Chronic treatment with physiological doses of estradiol affects the GH-IGF-1 axis and fat metabolism in young and middle-aged ovariectomized rats. Biogerontology 7:91-100.

Brown-Borg HM (2007) Hormonal regulation of longevity in mammals. Ageing Res Rev 6:28-45.

Bushnell CD (2008) Stroke in women: risk and prevention throughout the lifespan. Neurol Clin 26:1161-1176, xi.

Cardona-Gómez GP, DonCarlos L, Garcia-Segura LM (2000) Insulin-like growth factor I receptors and estrogen receptors colocalize in female rat brain. Neuroscience 99:751-760.

Cardona-Gómez GP, Mendez P, DonCarlos LL, Azcoitia I, Garcia-Segura LM (2002) Interactions of estrogen and insulin-like growth factor-I in the brain: molecular mechanisms and functional implications. J Steroid Biochem Mol Biol 83:211-217.

Carswell HV, Bingham D, Wallace K, Nilsen M, Graham DI, Dominiczak AF, Macrae IM (2004) Differential effects of 17beta-estradiol upon stroke damage in stroke prone and normotensive rats. J Cereb Blood Flow Metab 24:298-304.

Denti L, Annoni V, Cattadori E, Salvagnini MA, Visioli S, Merli MF, Corradi F, Ceresini G, Valenti G, Hoffman AR, Ceda GP (2004) Insulin-like growth factor 1 as a predictor of ischemic stroke outcome in the elderly. Am J Med 117:312-317.

Dubal DB, Wise PM (2001) Neuroprotective effects of estradiol in middleaged female rats. Endocrinology 142:43-48.

Dubal DB, Kashon ML, Pettigrew LC, Ren JM, Finklestein SP, Rau SW, Wise PM (1998) Estradiol protects against ischemic injury. J Cereb Blood Flow Metab 18:1253-1258.

Dubal DB, Zhu H, Yu J, Rau SW, Shughrue PJ, Merchenthaler I, Kindy MS, Wise PM (2001) Estrogen receptor $\alpha$, not $\beta$, is a critical link in estradiolmediated protection against brain injury. Proc Natl Acad Sci U S A 98:1952-1957.

Friend KE, Hartman ML, Pezzoli SS, Clasey JL, Thorner MO (1996) Both oral and transdermal estrogen increase growth hormone release in postmenopausal women-a clinical research center study. J Clin Endocrinol Metab 81:2250-2256. 
Garcia-Segura LM, Cardona-Gómez GP, Chowen JA, Azcoitia I (2000) Insulin-like growth factor-I receptors and estrogen receptors interact in the promotion of neuronal survival and neuroprotection. J Neurocytol 29:425-437.

Garcia-Segura LM, Azcoitia I, DonCarlos LL (2001) Neuroprotection by estradiol. Prog Neurobiol 63:29-60.

Garcia-Segura LM, Sanz A, Mendez P (2006) Cross-talk between IGF-I and estradiol in the brain: focus on neuroprotection. Neuroendocrinology 84:275-279.

Gluckman P, Klempt N, Guan J, Mallard C, Sirimanne E, Dragunow M, Klempt M, Singh K, Williams C, Nikolics K (1992) A role for IGF-1 in the rescue of CNS neurons following hypoxic-ischemic injury. Biochem Biophys Res Commun 182:593-599.

Gordon KB, Macrae IM, Carswell HV (2005) Effects of 17beta-oestradiol on cerebral ischaemic damage and lipid peroxidation. Brain Res 1036:155-162.

Guan J, Miller OT, Waugh KM, McCarthy DC, Gluckman PD (2001) Insulin-like growth factor-1 improves somatosensory function and reduces the extent of cortical infarction and ongoing neuronal loss after hypoxia-ischemia in rats. Neuroscience 105:299-306.

Himpe E, Degaillier C, Coppens A, Kooijman R (2008) Insulin-like growth factor-1 delays Fas-mediated apoptosis in human neutrophils through the phosphatidylinositol-3 kinase pathway. J Endocrinol 199:69-80.

Ho KK, O’Sullivan AJ, Weissberger AJ, Kelly JJ (1996) Sex steroid regulation of growth hormone secretion and action. Horm Res 45:67-73.

Hochner-Celnikier D, Manor O, Garbi B, Chajek-Shaul T (2005) Gender gap in cerebrovascular accidents: comparison of the extent, severity, and risk factors in men and women aged 45-65. Int J Fertil Womens Med 50:122-128.

Jezierski MK, Sohrabji F (2001) Neurotrophin expression in the reproductively senescent forebrain is refractory to estrogen stimulation. Neurobiol Aging 22:309-319.

Johnsen SP, Hundborg HH, Sørensen HT, Orskov H, Tjønneland A, Overvad K, Jørgensen JO (2005) Insulin-like growth factor (IGF) I, -II, and IGF binding protein-3 and risk of ischemic stroke. J Clin Endocrinol Metab 90:5937-5941.

Johnson AB, Sohrabji F (2005) Estrogen's effects on central and circulating immune cells vary with reproductive age. Neurobiol Aging 26:1365-1374.

Johnston BM, Mallard EC, Williams CE, Gluckman PD (1996) Insulin-like growth factor-1 is a potent neuronal rescue agent after hypoxic-ischemic injury in fetal lambs. J Clin Invest 97:300-308.

Jover T, Tanaka H, Calderone A, Oguro K, Bennett MV, Etgen AM, Zukin RS (2002) Estrogen protects against global ischemia-induced neuronal death and prevents activation of apoptotic signaling cascades in the hippocampal CA1. J Neurosci 22:2115-2124.

Jover-Mengual T, Zukin RS, Etgen AM (2007) MAPK signaling is critical to estradiol protection of CAl neurons in global ischemia. Endocrinology 148:1131-1143.

Laughlin GA, Barrett-Connor E, Criqui MH, Kritz-Silverstein D (2004) The prospective association of serum insulin-like growth factor I (IGF-I) and IGF-binding protein-1 levels with all cause and cardiovascular disease mortality in older adults: the Rancho Bernardo Study. J Clin Endocrinol Metab 89:114-120.

Law HK, Tu W, Liu E, Lau YL (2008) Insulin-like growth factor I promotes cord blood $\mathrm{T}$ cell maturation through monocytes and inhibits their apoptosis in part through interleukin-6. BMC Immunol 9:74.

Lee WH, Bondy CA (1993) Ischemic injury induces brain glucose transporter gene expression. Endocrinology 133:2540-2544.

Li J, Liang X, Wang Q, Breyer RM, McCullough L, Andreasson K (2008) Misoprostol, an anti-ulcer agent and PGE2 receptor agonist, protects against cerebral ischemia. Neurosci Lett 438:210-215.

Lin S, Fan LW, Rhodes PG, Cai Z (2009) Intranasal administration of IGF-1 attenuates hypoxic-ischemic brain injury in neonatal rats. Exp Neurol 217:361-370.

Liu D, Wu L, Breyer R, Mattson MP, Andreasson K (2005) Neuroprotection by the PGE2 EP2 receptor in permanent focal cerebral ischemia. Ann Neurol 57:758-761.

Liu F, Yuan R, Benashski SE, McCullough LD (2009) Changes in experimental stroke outcome across the life span. J Cereb Blood Flow Metab 29:792-802.

Macrae IM, Carswell HV (2006) Oestrogen and stroke: the potential for harm as well as benefit. Biochem Soc Trans 34:1362-1365.
Mason AS (1976) The menopause: the events of the menopause. R Soc Health J 96:70-71.

McCullough L, Wu L, Haughey N, Liang X, Hand T, Wang Q, Breyer RM, Andreasson K (2004) Neuroprotective function of the $\mathrm{PGE}_{2} \mathrm{EP}_{2}$ receptor in cerebral ischemia. J Neurosci 24:257-268.

Mendez P, Azcoitia I, Garcia-Segura LM (2003) Estrogen receptor alpha forms estrogen-dependent multimolecular complexes with insulin-like growth factor receptor and phosphatidylinositol 3-kinase in the adult rat brain. Brain Res Mol Brain Res 112:170-176.

Mendez P, Azcoitia I, Garcia-Segura LM (2005) Interdependence of oestrogen and insulin-like growth factor-I in the brain: potential for analysing neuroprotective mechanisms. J Endocrinol 185:11-17.

Murray B, Alessandrini A, Cole AJ, Yee AG, Furshpan EJ (1998) Inhibition of the p44/42 MAP kinase pathway protects hippocampal neurons in a cell-culture model of seizure activity. Proc Natl Acad Sci USA 95:11975-11980.

Namura S, Iihara K, Takami S, Nagata I, Kikuchi H, Matsushita K, Moskowitz MA, Bonventre JV, Alessandrini A (2001) Intravenous administration of MEK inhibitor U0126 affords brain protection against forebrain ischemia and focal cerebral ischemia. Proc Natl Acad Sci USA 98:11569-11574.

Niebrój-Dobosz I, Dziewulska D, Kwiecinski H (2004) Oxidative damage to proteins in the spinal cord in amyotrophic lateral sclerosis (ALS). Folia Neuropathol 42:151-156.

Niewada M, Kobayashi A, Sandercock PA, Kaminski B, Czlonkowska A, International Stroke Trial Collaborative Group (2005) Influence of gender on baseline features and clinical outcomes among 17,370 patients with confirmed ischaemic stroke in the international stroke trial. Neuroepidemiology 24:123-128.

Nordell VL, Scarborough MM, Buchanan AK, Sohrabji F (2003) Differential effects of estrogen in the injured forebrain of young adult and reproductive senescent animals. Neurobiol Aging 24:733-743.

Noshita N, Sugawara T, Hayashi T, Lewén A, Omar G, Chan PH (2002) Copper/zinc superoxide dismutase attenuates neuronal cell death by preventing extracellular signal-regulated kinase activation after transient focal cerebral ischemia in mice. J Neurosci 22:7923-7930.

Paxinos G, Watson C, Pennisi M, Topple A (1985) Bregma, lambda and the interaural midpoint in stereotaxic surgery with rats of different sex, strain and weight. J Neurosci Methods 13:139-143.

Petitti DB, Sidney S, Bernstein A, Wolf S, Quesenberry C, Ziel HK (1996) Stroke in users of low-dose oral contraceptives. N Engl J Med 335:8-15.

Poddar R, Paul S (2009) Homocysteine-NMDA receptor-mediated activation of extracellular signal-regulated kinase leads to neuronal cell death. J Neurochem 110:1095-1106.

Quesada A, Micevych PE (2004) Estrogen interacts with the IGF-1 system to protect nigrostriatal dopamine and maintain motoric behavior after 6-hydroxdopamine lesions. J Neurosci Res 75:107-116.

Quesada A, Romeo HE, Micevych P (2007) Distribution and localization patterns of estrogen receptor-beta and insulin-like growth factor-1 receptors in neurons and glial cells of the female rat substantia nigra: localization of ERbeta and IGF-1R in substantia nigra. J Comp Neurol 503:198-208.

Roquer J, Campello AR, Gomis M (2003) Sex differences in first-ever acute stroke. Stroke 34:1581-1585.

Rusa R, Alkayed NJ, Crain BJ, Traystman RJ, Kimes AS, London ED, Klaus JA, Hurn PD (1999) 17beta-estradiol reduces stroke injury in estrogendeficient female animals. Stroke 30:1665-1670.

Sawada M, Alkayed NJ, Goto S, Crain BJ, Traystman RJ, Shaivitz A, Nelson RJ, Hurn PD (2000) Estrogen receptor antagonist ICI182,780 exacerbates ischemic injury in female mouse. J Cereb Blood Flow Metab 20:112-118.

Schäbitz WR, Hoffmann TT, Heiland S, Kollmar R, Bardutzky J, Sommer C, Schwab S (2001) Delayed neuroprotective effect of insulin-like growth factor-I after experimental transient focal cerebral ischemia monitored with MRI. Stroke 32:1226-1233.

Schwab S, Spranger M, Krempien S, Hacke W, Bettendorf M (1997) Plasma insulin-like growth factor I and IGF binding protein 3 levels in patients with acute cerebral ischemic injury. Stroke 28:1744-1748.

Selvamani A, Sohrabji F (2008) Reproductive age modulates the impact of focal ischemia on the forebrain as well as the effects of estrogen treatment in female rats. Neurobiol Aging. Advance online publication. Retrieved April 11, 2010. doi:10.1016/j.neurobiolaging.2008.08.014.

Shumaker SA, Legault C, Kuller L, Rapp SR, Thal L, Lane DS, Fillit H, Stefan- 
ick ML, Hendrix SL, Lewis CE, Masaki K, Coker LH, Women's Health Initiative Memory Study (2004) Conjugated equine estrogens and incidence of probable dementia and mild cognitive impairment in postmenopausal women: Women's Health Initiative Memory Study. JAMA 291:2947-2958.

Simpkins JW, Rajakumar G, Zhang YQ, Simpkins CE, Greenwald D, Yu CJ, Bodor N, Day AL (1997) Estrogens may reduce mortality and ischemic damage caused by middle cerebral artery occlusion in the female rat. J Neurosurg 87:724-730.

Singh M, Sumien N, Kyser C, Simpkins JW (2008) Estrogens and progesterone as neuroprotectants: what animal models teach us. Front Biosci 13:1083-1089.

Siritho S, Thrift AG, McNeil JJ, You RX, Davis SM, Donnan GA, Melbourne Risk Factor Study Group (2003) Risk of ischemic stroke among users of the oral contraceptive pill: The Melbourne Risk Factor Study (MERFS) Group. Stroke 34:1575-1580.

Smith LE (2005) IGF-1 and retinopathy of prematurity in the preterm infant. Biol Neonate 88:237-244.

Strom JO, Theodorsson A, Theodorsson E (2009) Dose-related neuroprotective versus neurodamaging effects of estrogens in rat cerebral ischemia: a systematic analysis. J Cereb Blood Flow Metab 29:1359-1372.

Sultana R, Newman S, Mohmmad-Abdul H, Keller JN, Butterfield DA (2004) Protective effect of the xanthate, D609, on Alzheimer's amyloid beta-peptide (1-42)-induced oxidative stress in primary neuronal cells. Free Radic Res 38:449-458.

Torres Aleman I (2005) Role of insulin-like growth factors in neuronal plasticity and neuroprotection. Adv Exp Med Biol 567:243-258.

Toung TJ, Chen TY, Littleton-Kearney MT, Hurn PD, Murphy SJ (2004) Effects of combined estrogen and progesterone on brain infarction in reproductively senescent female rats. J Cereb Blood Flow Metab 24:1160-1166.

Towfighi A, Saver JL, Engelhardt R, Ovbiagele B (2007) A midlife stroke surge among women in the United States. Neurology 69:1898-1904.
Vegeto E, Belcredito S, Etteri S, Ghisletti S, Brusadelli A, Meda C, Krust A, Dupont S, Ciana P, Chambon P, Maggi A (2003) Estrogen receptoralpha mediates the brain antiinflammatory activity of estradiol. Proc Natl Acad Sci U S A 100:9614-9619.

Wakade C, Khan MM, De Sevilla LM, Zhang QG, Mahesh VB, Brann DW (2008) Tamoxifen neuroprotection in cerebral ischemia involves attenuation of kinase activation and superoxide production and potentiation of mitochondrial superoxide dismutase. Endocrinology 149:367-379.

Wang JM, Hayashi T, Zhang WR, Sakai K, Shiro Y, Abe K (2000) Reduction of ischemic brain injury by topical application of insulin-like growth factor-I after transient middle cerebral artery occlusion in rats. Brain Res 859:381-385.

Wang Z, Chen X, Zhou L, Wu D, Che X, Yang G (2003) Effects of extracellular signal-regulated kinase (ERK) on focal cerebral ischemia. Chin Med J (Engl) 116:1497-1503.

Wassertheil-Smoller S, Hendrix SL, Limacher M, Heiss G, Kooperberg C, Baird A, Kotchen T, Curb JD, Black H, Rossouw JE, Aragaki A, Safford M, Stein E, Laowattana S, Mysiw WJ, WHI Investigators (2003) Effect of estrogen plus progestin on stroke in postmenopausal women: the Women's Health Initiative: a randomized trial. JAMA 289:2673-2684.

Waters DL, Yau CL, Montoya GD, Baumgartner RN (2003) Serum sex hormones, IGF-1, and IGFBP3 exert a sexually dimorphic effect on lean body mass in aging. J Gerontol A Biol Sci Med Sci 58:648-652.

Williams DH, Wilkinson SE, Purton T, Lamont A, Flotow H, Murray EJ (1998) Ro 09-2210 exhibits potent anti-proliferative effects on activated T cells by selectively blocking MKK activity. Biochemistry 37:9579-9585.

Woodlee MT, Asseo-García AM, Zhao X, Liu SJ, Jones TA, Schallert T (2005) Testing forelimb placing "across the midline" reveals distinct, lesiondependent patterns of recovery in rats. Exp Neurol 191:310-317.

Yan YP, Sailor KA, Vemuganti R, Dempsey RJ (2006) Insulin-like growth factor-1 is an endogenous mediator of focal ischemia-induced neural progenitor proliferation. Eur J Neurosci 24:45-54. 